\title{
Organic Rankine Cycle and Its Working Fluid Selection-A Review
}

\author{
Suyog S. Bajaj ${ }^{*}$, Harshal B. Patil ${ }^{\dagger}$, Gorakh B. Kudal $^{\dagger}$ and S. P. Shisode ${ }^{\dagger}$ \\ †Department of Mechanical Engineering, MIT College of Engineering, Savitribai Phule Pune University, Pune India \\ Accepted 03 March 2016, Available online 15 March 2016, Special Issue-4 (March 2016)
}

\begin{abstract}
Renewed interest in waste heat power recovery has resulted in the development of Organic Rankine Cycle (ORC). An ORC is a technology that can convert thermal energy at relative low temperatures in the range of $80{ }^{\circ} \mathrm{C}$ to $350{ }^{\circ} \mathrm{C}$ into mechanical work and finally into electricity. It can play an important role to improve the energy efficiency of new or existing energy-intensive applications. It accounts for actual efficiencies of turbine and pump. It also accounts for refrigerant line pressure losses and finite boiler and condenser surface area. Depending on the industrial process the waste energy is rejected at different temperatures, which makes the optimal choice of the working fluid of great importance. This cycle program allows the use of different organic working fluids and various sources of waste heat. The current paper includes the study of ORC with due consideration to the working fluid and its application to waste recovery system.
\end{abstract}

Keywords: Organic Rankine Cycle (ORC), energy efficiency, working fluid

\section{Introduction}

Energy conservation in the world is becoming very important in recent years, especially the use of low grade temperature and small-scale heat sources. Energy extraction from industrial waste heat, biomass energy, solar energy, and turbine exhaust heat is becoming more popular. Organic Rankine Cycle is an effective way to convert these heat sources into electrical power. Organic Rankine Cycle offers the ability to deal with low temperature heat to generate power. The traditional Rankine Cycle which uses water as the working fluid needs much higher temperature heat source while Organic Rankine Cycle (ORC) can generate power at a much lower temperature. The heat source temperature can vary from 50 to over $250^{\circ} \mathrm{C}$. In recent years a lot of research has been conducted around the world and many ORC systems have been successfully installed in different countries, especially in USA, Canada, Germany and Italy.

Organic Rankine Cycles offer power production from renewable, waste heat and law-grade heat sources like, geothermal energy, biomass, solar energy and waste heat from industry and thermal power plants. Furthermore, Organic Rankine Cycle can be used to recover energy from exhaust gases from power trains, improving the fuel consumption and reducing their impact on climate changes.

Organic Rankine Cycle and working fluids have been widely studied in different scientific articles.

*Corresponding author: Suyog S. Bajaj
Some papers widely studied the usage of Organic Rankine Cycle ORC in different applications like waste heat recovery, geothermal power plants, biomass power plants and solar thermal power plants.

According to Roadmap 2050 from the European Climate Foundation 2010, the greenhouse emissions can be reduced by $80 \%$ in 2050 . This target can be achieved through the modification of the current energy system and the following modifications should be accomplished by 2050 :

- Increase effectiveness and reduce energy intensity of buildings by 950 TWHr/year and of Energy industry by $450 \mathrm{TWHr} /$ year.

- Use electricity instead of fossil fuels for transportation and space heating.

- Shift to renewable energies and clean power generation (Wind energy 25\%, PV1 19\%, CSP 25\%, Biomass $12 \%$, Geothermal $2 \%$ and Large hydro 12\%).

- Increase the grid capacity and reinforce the interregional transmission lines.

Photovoltaics (PV) is a method of generating electrical power by converting solar radiation into direct current electricity using semiconductors that exhibit the photovoltaic effect.

Concentrating Solar Power (CSP) systems use mirrors or lenses to concentrate a large area of sunlight, or solar thermal energy, onto a small area. 


\section{Organic Rankine Cycle}

In chemical industries as well as in the production of food, paper, cement etc. a lot of thermal energy is needed. During these processes the heat carrier cools down to a temperature level where the residual heat can't be used for the primary process. If the residual heat cannot be used for subsequent processes like drying granulates, the conversion of the waste heat to electricity may be an option. Organic Rankine Cycle (ORC) is a technology that can convert thermal energy at relative low temperatures in the range of 80 to 350 ${ }^{\circ} \mathrm{C}$ to electricity and can therefore play an important role to improve the energy efficiency of new or existing applications. Beside industrial waste heat alternative heat sources such as solar and geothermal energy as well as biomass can be applied. To better understand the Organic Rankine Cycle the process of a very simple conventional steam power plant (also called Clausius Rankine Cycle) is presented in Figure 2.1. In a steam power plant the thermal energy is converted to electricity as water passes through a sequence of state changes. To implement these state changes the components like a turbine with generator, condenser, feed pump and boiler are needed.

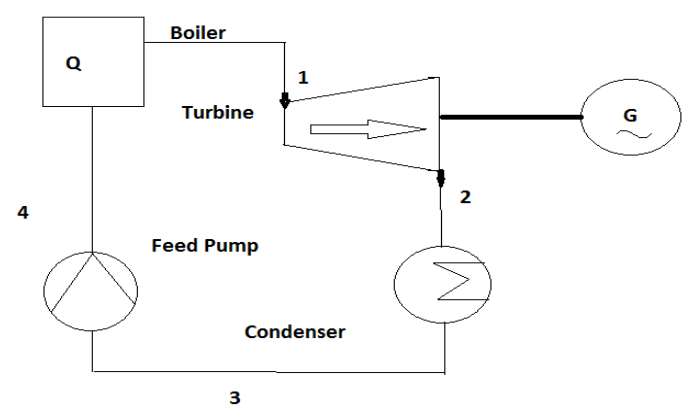

Fig.1 Schematic of a Conventional Rankine Cycle

Superheated steam passes into the turbine with high temperature and pressure (state 1). The turbine converts the thermal energy into mechanical energy, which is converted to electricity by the generator. While the turbine extracts energy from the steam the pressure and temperature decrease. If the expansion exceeds the saturated vapor curve wet steam occurs which may erode the turbine blades due to the impact of water droplets. The cool low pressure steam at turbine exit (state 2) is condensed to liquid water (state 3) and pressurized (state 4) by the feed pump. By adding heat to the water, steam is generated and superheated within the boiler. Now the condition before turbine (state 1) is reestablished and the thermodynamic cycle is closed. The water steam cycle is suitable for turbine inlet temperatures above $350^{\circ} \mathrm{C}$. At lower temperatures the efficiency significantly decreases and the danger of erosion due to droplets increases because the expansion goes deep into the wet steam region. By decreasing the turbine inlet pressure the steam quality at the end of the expansion can be improved. However, wet steam still exists and the efficiency additionally drops. ORC overcomes these problems by using an organic fluid, e. g. Pentane, instead of water (therefore it's called Organic Rankine Cycle). Organic fluids have lower boiling temperatures than water which make them suitable to explore heat potential with temperatures below $350^{\circ} \mathrm{C}$. By adoption of the working fluid to an existing waste heat temperature higher efficiencies can be achieved than with a conventional steam cycle.

\section{Comparison between Organic Rankine Cycle and Rankine Cycle}

The Organic Rankine Cycle has the same working principles and main components (evaporator, condenser, expander and pump) as the Steam Rankine Cycle. At the same time, there are some major differences between the two cycles. The differences are mainly related to the used working fluid in the cycle, the working fluid's thermo-physical properties, the heat source temperature and the cycle architecture. Organic Rankine Cycle can extract energy and generate power from much lower heat source temperature than traditional Rankine cycle.

To discuss the comparison between Organic Rankine Cycle and traditional Rankine Cycle several important aspects are highlighted below.

\subsection{Working Fluids}

The main difference between the two cycles is the working fluid used in each cycle. Water is the only working fluid used in Steam Rankine Cycle while there are hundreds of different working fluids which can be used in Organic Rankine Cycles. The designing and discovering of new working fluids is a continuous process. The cycle architecture, components size and shape, and economics are highly dependent on the chosen working fluid's thermo-physical properties. The thermo-physical, safety and environmental properties vary from one working fluid to another. The environmental and safety data are not available for many working fluids. The choice of the right working fluid is of key importance for the cycle efficiency, Net Work Out and etc.

\subsection{Normal Boiling Point and T-S diagram}

Most of organic fluids have a lower normal boiling point NBP than water. This property make organic fluids need a lower heat source temperature than water to evaporate and recover thermal energy from low grade heat sources. Fig. 2 shows the T-S diagram for water and some other working fluids which can be used in Organic Rankine Cycles. (Jamal Nouman, et al., 2012).

A remarkable difference in Fig. 2 is the entropy difference between the saturation liquid line and the saturation vapor line. 


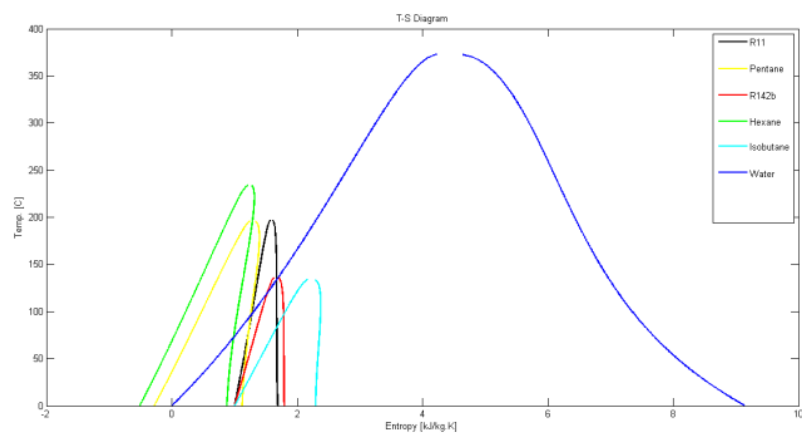

Fig.2 The T-S diagram of Different Fluids

Organic working fluids have a very low entropy change compared with water. Water as working fluid needs more thermal energy to change phase from saturated liquid to saturated vapor and can carry out more thermal energy per kg of water. The advantage of this property is that water needs a much lower mass flow rate than organic fluids to absorb the same amount of thermal power from a certain heat source. A higher mass flow rate leads to higher power consumption by pump and a higher piping system diameter should be used to overcome pressure losses related to high Reynolds number. A higher mass flow means also higher components size and pressure losses. Some organic fluids have a very low freezing temperature (due to low triple point) and the freezing problem in the condenser is eliminated even at extremely low ambient temperatures.

\subsection{Cycle Architecture}

The density of the organic fluid is of key importance for sizing cycle components which are highly dependent on the volumetric flow rate. Higher density means lower specific volume, lower volumetric flow rate and subsequently smaller component size. The pressure ratio, the density and the enthalpy change affect the design of expanders or turbines. In steam cycles the pressure ratio and enthalpy change over the expander is very high. This leads to using expanders with several expansion stages to reduce exergy losses and produce more work out. The pressure ratio and enthalpy change in ORC is lower and one or two stages expansion expanders are needed for many working fluids. Organic fluids offer less costly cycles and small sized piping system (due to high fluids density in evaporator and condenser). Organic Rankine Cycle has some other advantages compared to the conventional Steam cycle: a simple control system and a cheap and simple turbine are some of the advantages related to the cycle architecture.

A very common and typical problem in Steam cycles is drop formation at the end of expansion stages. These drops damage turbine blades and reduce the expander's life time and efficiency. To overcome this problem superheat is needed. The boiler in Rankine Cycle usually consists of three separate heat exchangers (preheater, evaporator and superheater).
In Organic Rankine Cycle the boiler consists of one or two heat exchangers.

Many ORC cycles use dry or isentropic fluids and there is no need for superheat. The expansion process can start directly from the saturation vapor line and working fluids leave the expander as superheated vapor. No attention needs to be paid to vapor quality at the end of the expansion process. Sometimes the recuperator or Internal Heat Exchanger IHE is not needed, especially when the working fluid leaves the expander at temperature much lower than the temperature at pump outlet.

\subsection{Condenser Pressure}

The condenser pressure in many ORC is higher than the atmospheric pressure. This is a desirable property because condensing pressure lower than the atmospheric pressure involves air infiltration problems in the cycle and reduce the cycle efficiency. The water condensing pressure at $298 \mathrm{~K}$ is $3.15 \mathrm{kPa}$, at the same time it is $105.49 \mathrm{kPa}$ for R11, $349.14 \mathrm{kPa}$ for Isobutane, 586.67 for DME and 271.04 for R236fa.

\subsection{Environmental and Safety Aspects}

Water as working fluid is environmentally friendly, non-flammable, non-toxic, has no ozone depletion potential ODP and no global warming potential GWP. Many of the organic fluids have a high negative impact on the greenhouse effect and ozone depletion problems. At the same time these organic fluids can be flammable and toxic. Unknown safety and environmental data is another problem connected to some organic fluids.

\section{Thermodynamics of Organic Rankine Cycle and Working Principle}

The working principles for the ideal Organic Rankine Cycle are similar to the ideal Rankine Cycle. The condensate working fluid is pumped from the condenser where the pressure is low to the evaporator where the pressure is high. The process takes place at constant entropy. The high pressure liquid enters the evaporator and absorbs the thermal energy from heat source at constant pressure. In this process the refrigerant changes the phase from saturated liquid to saturated or superheated vapor. The external heat source can be waste heat from industry, geothermal heat, solar heat, biomass etc. The high pressure saturated or superheated vapor leaves the evaporator and expands through an expander at constant entropy to produce mechanical work. Under the expansion process, the pressure decreases to condenser pressure. After expansion process the working fluid leaves the expander and enters the condenser as unsaturated, saturated or superheated vapor depending on working conditions and the type of used working fluid. In the condenser, the working fluid condensates and changes 
phase to saturated or undercooled liquid with the help of a heat sink, and then the cycle is repeated.

(Jamal Nouman, et al,2012)

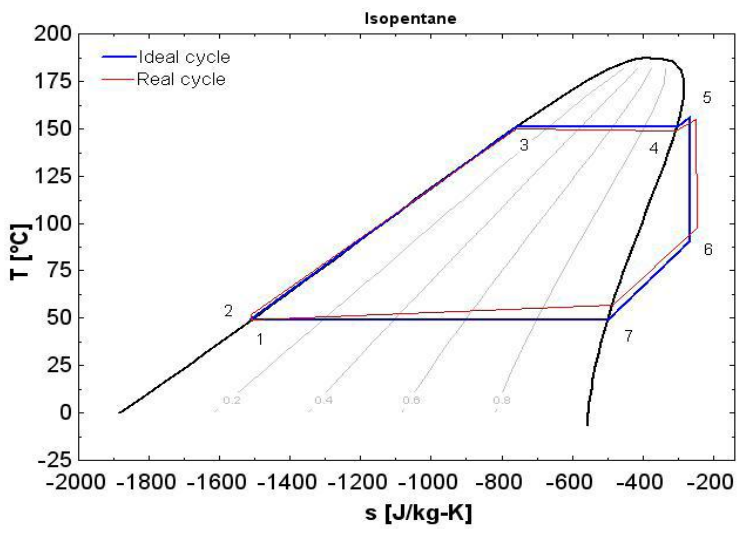

Fig.3 The ideal and the Real Organic Rankine Cycle

In the real cycle the compression and expansion processes are not isentropic and there are always some losses in the pump and the expander. The heat addition and heat rejection processes are not isobaric and there are always pressure losses in the piping system. The irreversibility affects very much the performance of the thermodynamic system. (Mago, P.J., Chamra, L.M. and Somayaj, C., et al, 2007; Aljundi I. H., et al, 2011)

In a real cycle, there are two main sources for entropy generation and these sources are external and internal. The internal entropy generation occurs due to:

- Pressure drop because of friction in the system associated pipes

- Un-isentropic compression and expansion in the compressor or expander

- Internal transfer of energy over a finite temperature difference in the components.

And the external entropy generation occurs due to:

- The mechanical losses during work transfer

- Heat transfer over the finite temperature difference

\section{Working Fluid Selection}

The working fluid selection has been treated in many papers and scientific articles. Most of the articles and papers are based on theoretical studies of working fluids using simulations of thermodynamic models. Many scientific articles mainly treat the thermophysical properties of working fluids with a focus on thermal efficiency, second law efficiency, Net Work Out, etc.

The choice of the optimal working fluid depends basically on the heat source and the heat sink temperature. For any heat temperature level there are a number of candidates which show a good match between heat source and heat sink temperatures and cycles boundary conditions. The choice the right working fluid is not an easy process. The fluid selection process is a trade-off between thermodynamic specifications, safety, environmental and economy aspects. The following criteria should be taken in consideration in order to figure out the best candidates. (Mago, P.J., Chamra L.M. and Somayajl, C., et al., 2007)

\subsection{Thermodynamic Properties}

Thermodynamic properties are of key importance in the design process of Organic Rankine Cycles, regarding optimal energy utilization and reducing energy losses. The following are some important thermodynamic properties for working fluids:

- For a certain heat sink and heat source the Net Power Out, the thermal efficiency and the second law efficiency should be as high as possible.

- The condensing pressure should be higher than the atmospheric pressure to avoid leakage issues.

- In sub-critical cycles the critical pressure for the working fluid must be higher than the pressure in the evaporator.

- Vapor density: The higher the density, the lower the specific volume and volumetric flow rate. Low volumetric flow is desirable to achieve smaller component and more compact machines. Low density fluids have high specific volume and need bigger components (heat exchangers and expander). A bigger component size leads to more expensive units and more costly systems. Furthermore, a high specific volume increases the pressure drop in the heat exchangers and needs higher pump work.

- Saturation vapor line: Regarding saturation vapor line, there are three kinds of working fluids which are dry, isentropic and wet working fluids. Using wet fluid may lead to drop formation at the end of expansion process. The drop formation can lead to serious damages in turbo machinery expanders. To avoid drop formation, superheat is necessary but it needs a bigger and more expensive evaporator. By using dry or isentropic fluids, the problems associated to drop formation can be eliminated.

- Large enthalpy variation in the turbine leads to high Net Work Out.

- Higher convective heat coefficient and high-thermal conductivity increases the heat transfer process between the heat source, the heat sink and the working fluid.

- High heat capacity (CP) of the liquid leads to better energy recovery from the heat source and decrease the mass flow rate of the working fluid.

- The working fluid should be thermally and chemically stable.

\subsection{Environmental and Safety Criteria}

Environmental and safety criteria are of key importance in working fluid selection however many working are phased out or on the way to be. The phased out working fluids have high ozone depletion 
potential ODP and global warming potential GWP. Some working fluids have good thermodynamic properties but at the same time have undesirable environmental and safety effects.

According to EC Regulation 2037/2000, many working fluids like CFC, CFCs and HCFCs refrigerant are already phased out. These refrigerants are banned due to their ozone depletion potential ODP and global warming potential GWP.

The EC Regulation 2037/2000 affects users, producers, suppliers, maintenance and servicing engineers, and those involved in the disposal of all ozone depletion substances ODS. The new regulation includes chlorofluorocarbons (CFCs), hydrochlorofluorocarbons (HCFCs), halons, trichloroethane, carbon tetrachloride and bromochloromethane (CBM). These refrigerants are mainly used in refrigeration, air-conditioning, foam blowing, as solvents and in firefighting.

\section{Environmental Data}

The environmental data includes global warming potential GWP and ozone depilation potential ODP.

- Global Warming Potential (GWP): The number of Global Warming Potential (GWP) refers to the amount of global warming caused by a certain working fluid relative to $\mathrm{CO}_{2}$ for a 100 year timeframe. Or in other words, the GWP is the ratio of the warming caused by a substance to the warming caused by a similar mass of carbon dioxide. Thus, the GWP of $\mathrm{CO}_{2}$ is defined to be 1.0. Water has a GWP of 0 . Carbon dioxide is used as reference because it has the greatest net impact on global warming. There are some other refrigerants which typically have a higher GWP than carbon dioxide but they are available in much smaller quantities. It is worth here to mention that some GWP values like $(\sim 20)$ or $(<20)$ reflect uncertainty in calculations and there is no scientific consensus at this time.

- Ozone Depletion Potential (ODP): The Ozone Depletion Potential (ODP) refers to refrigerants' and other chemicals' ability to destroy stratospheric ozone relative to R11. According to the United States Environmental Protection Agency EPA the Ozone Depletion Potential ODP is: "The ratio of the impact on ozone of a chemical compared to the impact of a similar mass of CFC11. Thus, the ODP of CFC-11 is defined to be 1.0. Other CFCs and HCFCs have ODPs that range from 0.01 to 1.0. The halons have ODPs ranging up to 10 . Carbon tetrachloride has an ODP of 1.2, and methyl chloroform's ODP is 0.11 . HFCs have zero ODP because they do not contain chlorine". The Ozone Depletion Potential ODP is a very important issue in working fluid selection. The selected working fluids shouldn't have a very low or zero Ozone Depletion Potential ODP. Working fluids with any ODP have been or will be phased out, as required by the Monorail Protocol.

\subsection{Guideline for selecting the most appropriate working} fluid

- Thermodynamic performance: the efficiency and/or output power should be as high as possible for given heat source and heat sink temperatures. This performance depends on a number of interdependent thermodynamic properties of the working fluid: critical point, acentric factor, specific heat, density, etc. It is uneasy to define an optimum for each specific thermodynamic property independently. The solution consists in simulating the cycle with a thermodynamic model and compare the fluids in terms of cycle efficiency and/or output power.

- Positive or isentropic saturation vapor curve. As previously detailed in the case of water, a negative saturation vapor curve ("Wet" fluid) leads to droplets at the end of the expansion. The vapor must therefore be superheated at the turbine inlet to avoid turbine damages. In the case of positive saturation vapor curve("Dry" fluid), a recuperator can be used in order to increase cycle efficiency.

- High vapor density: this parameter is of key importance, especially for fluids showing a very low condensing pressure (e.g. silicon oils). A low density leads to a higher volume flow rate: the pressure drops in the heat exchangers are increased, and the size of the expander must be increased. This has a non-negligible impact on the cost of the system. It should however be noted that larger volume flow rates might allow the design of turbo expanders, for which the size is not a crucial parameter.

- Low viscosity: a low viscosity both in the liquid and vapor phases is required to maintain high heat transfer coefficients and low friction losses in the heat exchangers.

- High conductivity is required to obtain a high heat transfer coefficient in the heat exchangers.

- Acceptable evaporating pressure: as already stated with water, high pressures usually lead to higher investment costs and increased complexity.

- Positive condensing gauge pressure: the low pressure should be higher than the atmospheric pressure in order to avoid air infiltration in the cycle.

- High stability temperature: unlike water, organic fluids usually suffer chemical deteriorations and decomposition at high temperatures. The maximum heat source temperature is therefore limited by the chemical stability of the working fluid.

- The melting point should be lower than the lowest ambient temperature through the year to avoid the freezing of the working fluid.

- High safety level: Safety includes two main parameters: the toxicity and the flammability. The ASHRAE Standard 34 classifies refrigerants in safety groups and can be used for the evaluation of a fluid. 
- Low Ozone Depleting Potential (ODP): The ozone depleting potential is measured with comparison to the ODP of the R11, set to the unity. The ODP of current refrigerants is either null either very close to zero, since non-null ODP fluids are progressively being phased out by the Montreal Protocol.

- Low Greenhouse Warming Potential (GWP): GWP is measured with comparison to the GWP of $\mathrm{CO} 2$, set to the unity. Although some refrigerants can reach a GWP value as high as 1000 , there is no legislation restricting the use of high GWP fluids. Good availability and low cost: Fluids already used in refrigeration or in the chemical industry are easier to obtain and more cost-effective.

\section{Applications of ORC}

Organic Rankine Cycle can efficiently be used in many applications in order to generate mechanical work or electrical power and following are some of the applications. (A. Rettig, M. Lagler, T. Lamare, S. Li, V. Mahadea, S. McCallion, J. Chernushevich, et al, 2011)

\subsection{Waste Heat Recovery}

Waste heat recovery is a process in which the energy is extracted from waste heat which comes from many processes, especially in industrial applications. In some applications waste heat boilers, recuperators and regenerators are used in order to directly recover and redirect heat to the process itself. In steam cycles the economics of waste heat recovery don't justify when the temperature of the wasted heat is low. The Organic Rankine Cycle can be used to produce electricity from low grade heat sources.

\subsection{Solar Thermal Power}

The solar thermal power is a well-proven technology. The parabolic dish, the solar tower and the parabolic though are three different technologies used to extract power from solar thermal. The parabolic tower can work at a temperature range of $300{ }^{\circ} \mathrm{C}-400{ }^{\circ} \mathrm{C}$. For a long time this technology was linked to the traditional Steam Rankine Cycle for power generation. The Organic Rankine Cycle seems to be a more promising technology. However, the Steam Rankine Cycle needs higher temperature and a higher installed power in order to be profitable. The Organic Rankine Cycle can work at lower temperatures, offers a smaller component size and needs much lower investment cost compared to steam cycles. The installed power can be reduced to $\mathrm{kW}$ scale.

\subsection{Geothermal Power Plants}

The geothermal power has the potential to supply renewable electricity to a large number of communities. In 2007 was $1 \%$ of world's electricity supplied by geothermal sources. This source of energy is clean and renewable and the production can be highly efficient. Dry steam power plants, flash steam power plants and binary cycle power plants are three different technologies used to extract power in geothermal power plants.

\subsection{Biomass Power Plants}

The traditional fossil fuels are expensive and have a huge impact on climate change and the greenhouse effect. Biomass is a cheap and environmentally friendly energy source and is experiencing a strong market growth. It can be used efficiently to produce both heat and power by fueling a combined heat and power CHP system. Biomass fuels exist in many forms:

- Wood and wood wastes and combustible agriculture wastes

- Biogas from organic materials such as farm waste or wastewater sludge

- Black liquor which is a byproduct of the pulping process.

Trees, energy crops, agriculture residues, food waste and industrial waste and their co-products are some of the typical sources of biomass. Utilizing biomass fuels has many valuable benefits in regard to mitigating global warming, climate changes and economics associated with fuel prices. Biomass displaces purchased fossil fuel, decreasing tipping fees associated with waste disposal and freeing up landfill space. The most important difference between biomass and fossil fuels is that biomass takes carbon out of atmosphere while it is growing and returns it as it burns. (Sylvain Quoilin, SebastienDeclaye, Arnaud Legros, Ludovic Guillaume, Vincent Lemort, et al, 2012)

\section{Conclusions}

The selection of optimal working fluid for Organic Rankine Cycle is not an easy process. There are many different working fluids to choose among and many criteria should be taken inconsideration. Some working fluids have good thermodynamic properties but at the same time have undesirable environmental and safety data. Other fluids have a good environmental and safety data but they are not efficient thermodynamically. There is no ideal working fluid can achieve all the desired criteria and the fluid selection process is a trade-off between thermodynamic environmental and safety properties.

From a thermodynamic perspective, the selection of the optimal working fluid depends basically on the heat source and the heat sink temperatures. For every heat source and heat sink temperature there are a number of working fluid candidates. The most selected working fluids should have good thermodynamic properties like high thermal efficiency, second law efficiency and Net Work Out. The volumetric flow rate and the working fluid viscosity should be as low as possible to reduce the components size, pressure losses and the work 
needed for pumping. The thermal conductivity of working fluid is another important aspect that should be taken in consideration in working fluid selection process.

\section{References}

Jamal Nouman, seminar report (2012), Comparative studies and analyses of working fluids for Organic Rankine Cycles - ORC, KTH engineering and Management.

A. Rettig, M. Lagler, T. Lamare, S. Li, V. Mahadea, S. McCallion, J. Chernushevich (2011) , Application of Organic Rankine Cycles (ORC), World Engineer Convention, Geneva .

Sylvain Quoilin, SébastienDeclaye, Arnaud Legros, Ludovic Guillaume, Vincent Lemort (2012), Working fluid selection and operating maps for Organic Rankine Cycle expansion Machines, International Compressor Engineering Conference at Purdue, 19, pp.1546 pg10
United Nations, (2008), International Standard Classification of All Economic Activities

Mago, P.J., Chamra, L.M. and Somayajl, C. (2007), Performance analysis of different working fluids for use in organic rankine cycles, Journal of Power and Energy, pp. 221-255.

Aljundi, I. H. (2011), Effect of dry hydrocarbons and critical point temperature on the efficiencies of organic Rankine cycle, Renewable Energy, 36(4), 1196-1202.

Harinck, J., Turunen-Saaresti, T., Colonna, P., Rebay, S., \& van Buijtenen, J. (2010), Computational Study of a HighExpansion Ratio Radial Organic Rankine Cycle Turbine Stator, Journal of Engineering for Gas Turbines and Power, 132(5), 054501-6

Ormat Technologies, Website: http:// www.ormat.com/ global-project 